\title{
The view of pulmonologists on palliative care for patients with COPD: a survey study
}

\author{
This article was published in the following Dove Press journal: \\ International Journal of COPD \\ 17 January 2017 \\ Number of times this article has been viewed
}

\author{
RG Duenk' \\ C Verhagen' \\ PNR Dekhuijzen² \\ KCP Vissers' \\ $Y$ Engels ${ }^{1, *}$ \\ Y Heijdra ${ }^{2}$ *
}

'Department of Anesthesiology, Pain and Palliative Medicine, ${ }^{2}$ Department of Lung Diseases, Radboud University Nijmegen Medical Centre, Nijmegen, the Netherlands

*These authors contributed equally to this work
Correspondence: RG Duenk Department of Anesthesiology, Pain and Palliative Medicine, Radboud University Nijmegen Medical Centre, PO Box 910I, 6500 HB Nijmegen, the Netherlands

$\mathrm{Tel}+3$ I 243666254

Fax +3I $2436 \mid 3585$

Email ria.duenk@radboudumc.nl
Introduction: Early palliative care is not a common practice for patients with COPD. Important barriers are the identification of patients for palliative care and the organization of such care in this patient group.

Objective: Pulmonologists have a central role in providing good quality palliative care for patients with COPD. To guide future research and develop services, their view on palliative care for these patients was explored.

Methods: A survey study was performed by the members of the Netherlands Association of Physicians for Lung Diseases and Tuberculosis.

Results: The 256 respondents $(31.8 \%$ ) covered $85.9 \%$ of the hospital organizations in the Netherlands. Most pulmonologists (92.2\%) indicated to distinguish a palliative phase in the COPD trajectory, but there was no consensus about the different criteria used for its identification. Aspects of palliative care in COPD considered important were advance care planning conversation (82\%), communication between pulmonologist and general practitioner $(77 \%)$, and identification of the palliative phase $(75.8 \%)$, while the latter was considered the most important aspect for improvement (67.6\%). Pulmonologists indicated to prefer organizing palliative care for hospitalized patients with COPD themselves $(55.5 \%)$, while $30.9 \%$ indicated to prefer cooperation with a specialized palliative care team (SPCT). In the ambulatory setting, a multidisciplinary cooperation between pulmonologist, general practitioner, and a respiratory nurse specialist was preferred (71.1\%).

Conclusion: To encourage pulmonologists to timely initiate palliative care in COPD, we recommend to conduct further research into more specific identification criteria. Furthermore, pulmonologists should improve their skills of palliative care, and the members of the SPCT should be better informed about the management of COPD to improve care during hospitalization. Communication between pulmonologist and general practitioner should be emphasized in training to improve palliative care in the ambulatory setting.

Keywords: proactive palliative care, pulmonologists, identification, organization, cooperation

\section{Introduction}

COPD is a progressive life-threatening disease and the third leading cause of death worldwide. ${ }^{1}$ Symptoms at the end of life are as severe as or even worse than those of patients with advanced cancer. ${ }^{2}$ Even so, compared to patients with cancer, palliative care is not a common practice for patients with COPD. ${ }^{3}$ This may be due to the fact that historically the focus of palliative care has been based on oncology. ${ }^{4}$ But, according to the definition of the World Health Organization (WHO), palliative care is intended for any life-threatening disease by means of early identification, assessment, and treatment of pain and other problems, such as physical, psychosocial, and spiritual in order to prevent and relieve suffering. ${ }^{5}$ The palliative phase, thus, comprises of a 
much longer period than the terminal or dying phase only. It implies that palliative care, as opposed to hospice care, is not limited to the terminal phase and can be given at an early stage alongside curative care. So, also patients with COPD may benefit from early palliative care without denying active disease-oriented treatment.

Important barriers in the provision of palliative care for patients with COPD are the identification of patients for palliative care and the organization of such care ${ }^{6}$ COPD has a gradual decline punctuated by acute severe exacerbations, any one of which may be fatal. ${ }^{7,8}$ This unpredictable disease course hampers clinicians to timely initiate discussions about palliative care. ${ }^{9,10}$ A debate has started among professionals whether prognosis, curability, palliative needs, or a combination of these factors should mark the start of a palliative trajectory in patients with COPD, but consensus has not yet been established. ${ }^{11}$ Consensus also needs to be established about the optimal organization of palliative care. ${ }^{9}$ Patients with advanced COPD are often homebound until they enter an acute phase with hospitalization. This requires community-based care with continuity of care during hospitalization. ${ }^{12}$ Continuity of palliative care, thus, can only be achieved with a coordinated, collaborative, and multidisciplinary care approach. ${ }^{13}$ Therefore, general practitioners (GPs), pulmonologists, respiratory nurses, and palliative care specialists should collaborate to optimize palliative care delivery for patients with COPD. How this coordinated care should be successfully organized across the entire illness trajectory is not yet decided. ${ }^{14,15}$

To facilitate delivery of palliative care to patients with COPD for clinicians, the Lung Alliance Netherland, the Dutch society for chronic lung diseases, developed a guideline on palliative care for patients with COPD in $2010 .{ }^{16}$ This guideline also provides recommendations about the start and the organization of palliative care based on literature, but it is unknown to what extent clinicians use this guideline.

Since pulmonologists have a central role in providing good quality care for patients with COPD, they are in the front line to recognize palliative care needs in this patient group. For that reason, it has been advised that they take the lead in developing services. ${ }^{17}$ Therefore, the objective of this study was to explore the view of pulmonologist in the Netherlands on: 1) palliative care for patients with COPD in general, 2) identification of patients with COPD for palliative care, 3) important aspects of palliative care for patients with COPD, and 4) organization of palliative care for patients with COPD.

\section{Methods \\ Study design}

A national survey was performed to explore the view of pulmonologists in the Netherlands on palliative care for patients with COPD.

\section{Study procedure}

Mail and postal addresses of all pulmonologists and pulmonologists in training (i.t.) were obtained from the Netherlands Association of Physicians for Lung Diseases and Tuberculosis (NVALT). Of all 846 members registered at the NVALT, 42 were excluded because they worked in a foreign practice $(n=25)$ and were a tuberculosis physician $(n=15)$ or an epidemiologist ( $n=2$; Figure 1). In total, 804 members, 575 pulmonologists (66.1\% male, 33.9\% female) and 229 pulmonologists i.t. (31\% male and $69 \%$ female) were invited to participate in the study in April 2015. They received the digital NVALT newsletter with a link to a digital survey. An email reminder was sent 2 weeks later. In June 2015, a paper version of the survey was sent to invite nonresponders to participate. All questionnaires received before 15 August 2015 were included in the analysis. This study was approved by the Medical Ethics Committee (CMO) of the Radboud University Medical Center, Nijmegen (METC number 2012/260). Based on criteria established by the Central Committee on Research involving Human Subjects (CCMO) in the Netherlands, the study was reviewed as non interventional and for that reason pulmonologists did not have to sign an informed consent form in order to participate.

\section{Survey}

The survey consisted of demographic characteristics and questions about proactive palliative care for patients with COPD (Supplementary materials). The demographic characteristics were assessed based on the position (pulmonologist or pulmonologist i.t.), clinician (active or nonactive), gender, name and place of the hospital, location of the hospital if appropriate, and the number and gender of pulmonologists working in their association of pulmonologists (or if not applicable, hospital).

The questions about proactive palliative care for patients with COPD concerned the view of pulmonologists or pulmonologist i.t. on the following four main subjects: 1) palliative care for patients with COPD in general (five questions), 2) identification of patients with COPD for palliative care (one question), 3) content of palliative care for patients with COPD (two questions), and 4) organization of palliative care for patients with COPD (five questions). 


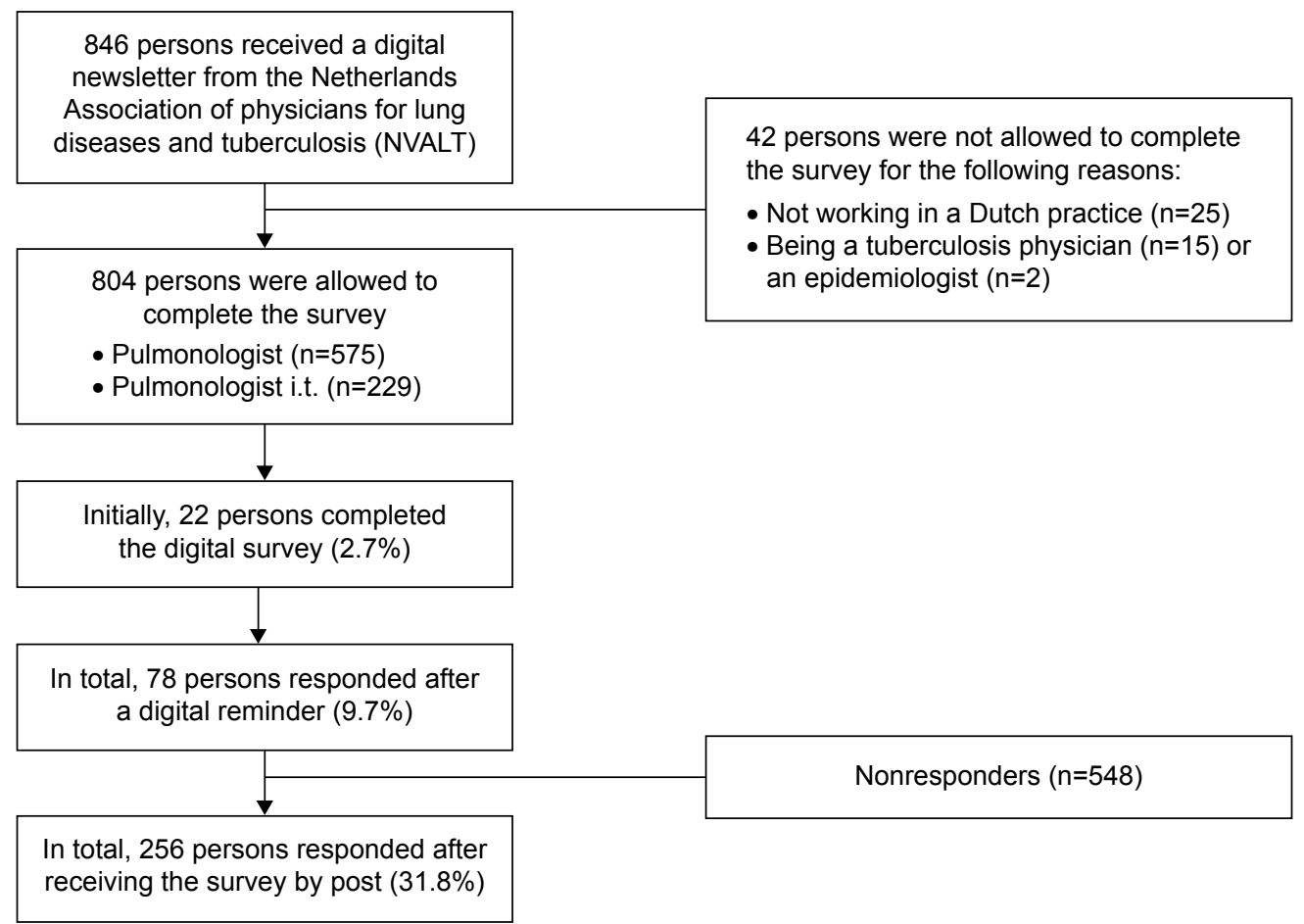

Figure I Study flow diagram.

Abbreviation: i.t., in training.

The questions about palliative care for patients with COPD in general concerned whether pulmonologists or pulmonologists i.t. think that palliative care for patients with COPD is desirable, whether they distinguish a palliative phase in the COPD disease trajectory, if not why, whether they use the guideline palliative care for patients with COPD (2011), and if not why. The view of pulmonologists and pulmonologists i.t. concerning the organization of palliative care for patients with COPD started with the question whether the hospital has a specialized palliative care team (SPCT) at their disposal, and if yes, whether this team is also involved in the care of patients with COPD. Next, their opinion was asked about who should organize the delivery of palliative care for patients with COPD, respectively, during hospitalization and in the ambulatory setting.

In total, 13 questions were presented in this second part: 12 multiple choices and one last open question about what aspects of palliative care in COPD they thought were missing or should be developed in the near future. In seven multiple choice questions, only one answer was possible. In the other five multiple choice questions, multiple answers were possible and the opportunity was given for an open answer under the choice "other namely".

\section{Statistical analyses}

Descriptive statistics were conducted. Noncontinuous variables were reported as frequencies. Statistical analyses were performed with SPSS 20.0 (IBM SPSS Statistics, Armonk, NY, USA).

\section{Results \\ Study population}

In total, 256 of 804 pulmonologists and pulmonologists i.t. (31.8\%) completed the survey (Figure 1). The responding pulmonologists and pulmonologists i.t. covered 73 of the 85 hospital organizations ( $85.9 \%$ ) of all general and academic hospitals in the Netherlands. A hospital organization consists of one or more hospital locations which fall under the same board of directors

\section{Demographic characteristics}

The characteristics of the study population are presented in Table 1. Of the study population of 256 respondents, 197 were pulmonologists $(60.4 \%$ male, $39.6 \%$ female) and 59 were pulmonologists i.t. ( $28.8 \%$ male, $71.2 \%$ female). Two pulmonologists were not active clinicians since one was a researcher and the other retired.

\section{Palliative care for patients with COPD in general}

In total, 253 respondents (98.8\%) answered that palliative care for patients with COPD is desirable and 236 respondents $(92.2 \%)$ answered that they distinguish a palliative phase in 
Table I Characteristics of the study population

\begin{tabular}{ll}
\hline Study population $(\mathbf{N}=\mathbf{2 5 6})$ & $\mathbf{N}(\%)$ \\
\hline Position & \\
$\quad$ Pulmonologist & $197(77)$ \\
Pulmonologist i.t. & $59(23)$ \\
Clinician & \\
$\quad$ Active & $254(99.2)$ \\
Gender & \\
$\quad$ Male & $136(53.1)$ \\
Work place & \\
General hospital & $202(78.9)$ \\
Academic hospital & $45(17.6)$ \\
Categorical hospital* & $8(3.1)$ \\
Missing & $\mathrm{I}(0.4)$ \\
\hline
\end{tabular}

Note: *Specialized pulmonary hospital (sleep, rehabilitation, or cancer).

Abbreviation: i.t., in training.

the COPD trajectory. The 19 respondents (7.4\%) that did not distinguish a palliative phase in the COPD trajectory gave as reasons (more than one answer possible) that there is no distinction between curative and palliative care (63.2\%), that they find the criteria for the start of palliative care difficult (26.3\%), that an SPCT is not available for patients with COPD (5.3\%), and/or other reasons (15.8\%).

The percentage of pulmonologists that use the guideline palliative care for patients with COPD is presented in Figure 2.

\section{Identification of patients with COPD for palliative care}

Each of the formulated criteria mentioned in the survey to possibly identify patients with COPD for palliative care was

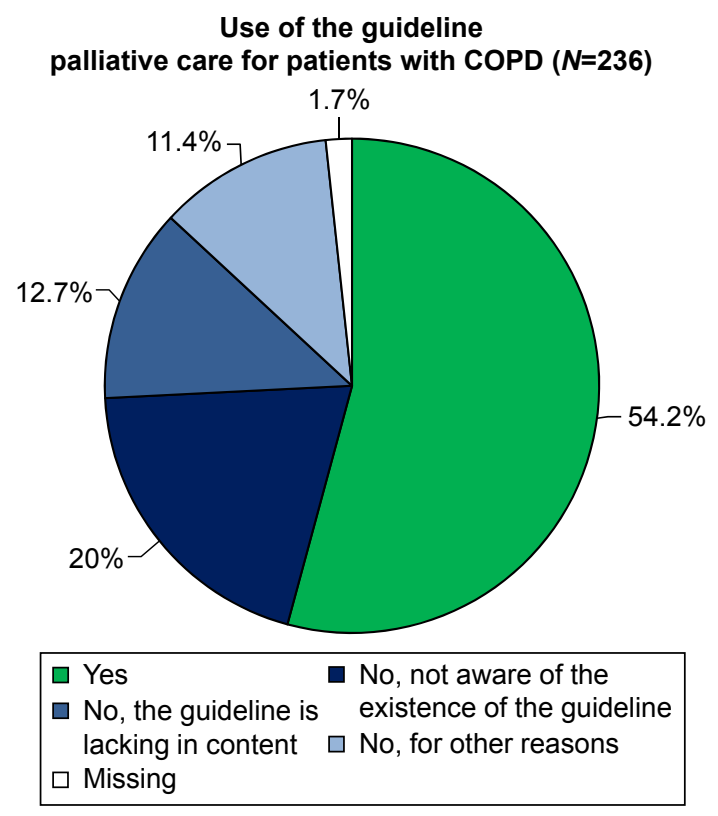

Figure 2 The percentage of pulmonologists that use the guideline palliative care for patients with COPD. indicated by a larger or smaller part of the 236 respondents who distinguished a palliative phase in the COPD trajectory. Besides, all respondents indicated use of more than one criteria. The criteria and the percentage of respondents that mentioned use of each criterion to identify patients with COPD for palliative care are presented in Figure 3. Of all respondents, $11.4 \%$ mentioned use of other criteria, such as a combination of factors $(2.5 \%)$, no treatment options left $(2.1 \%)$, and the surprise question (negative answer to the question: would I, as pulmonologist, be surprised if the patient would die in the next year [1.7\%]).

\section{Aspects of palliative care for patients with COPD \\ Important aspects}

Each formulated aspect of palliative care was at least chosen once. Besides, each respondent indicated more than one aspect (Figure 4). Of all respondents, 2\% also mentioned other aspects to be important. These were mainly remarks of involved pulmonologists concerning the aspect content of palliative care, such as the response "involvement of informal caregivers".

\section{Improvement desirable}

Each formulated aspect of palliative care was chosen by at least one respondent as being desirable to improve. Besides, each respondent chose more than one aspect (Figure 4). Of all respondents, $2 \%$ mentioned that improvement is desirable for other aspects. These were mainly remarks of involved pulmonologists concerning the improvement of the aspect content of palliative care, such as the response "options for relief of suffering".

\section{The organization of palliative care for patients with COPD}

\section{Specialized palliative care team}

Of all respondents, $87.1 \%$ indicated the presence of an SPCT in the hospital, while $53.1 \%$ indicated the involvement of the SPCT in the care of patients with COPD (Figure 5). Respondents from 70 of the 73 hospital organizations $(95.9 \%)$ indicated that they have an SPCT at their disposal, but within 11 hospital organizations (15.1\%) respondents were not in full agreement about this. Within these 70 hospital organizations, the respondents of 32 hospital organizations $(45.7 \%)$ were not unanimous when asked whether the SPCT in their organization was involved in the care of patients with COPD. Besides, some of the pulmonologists who confirmed this question placed a remark saying: theoretically, this is possible but in practice it is less common. 


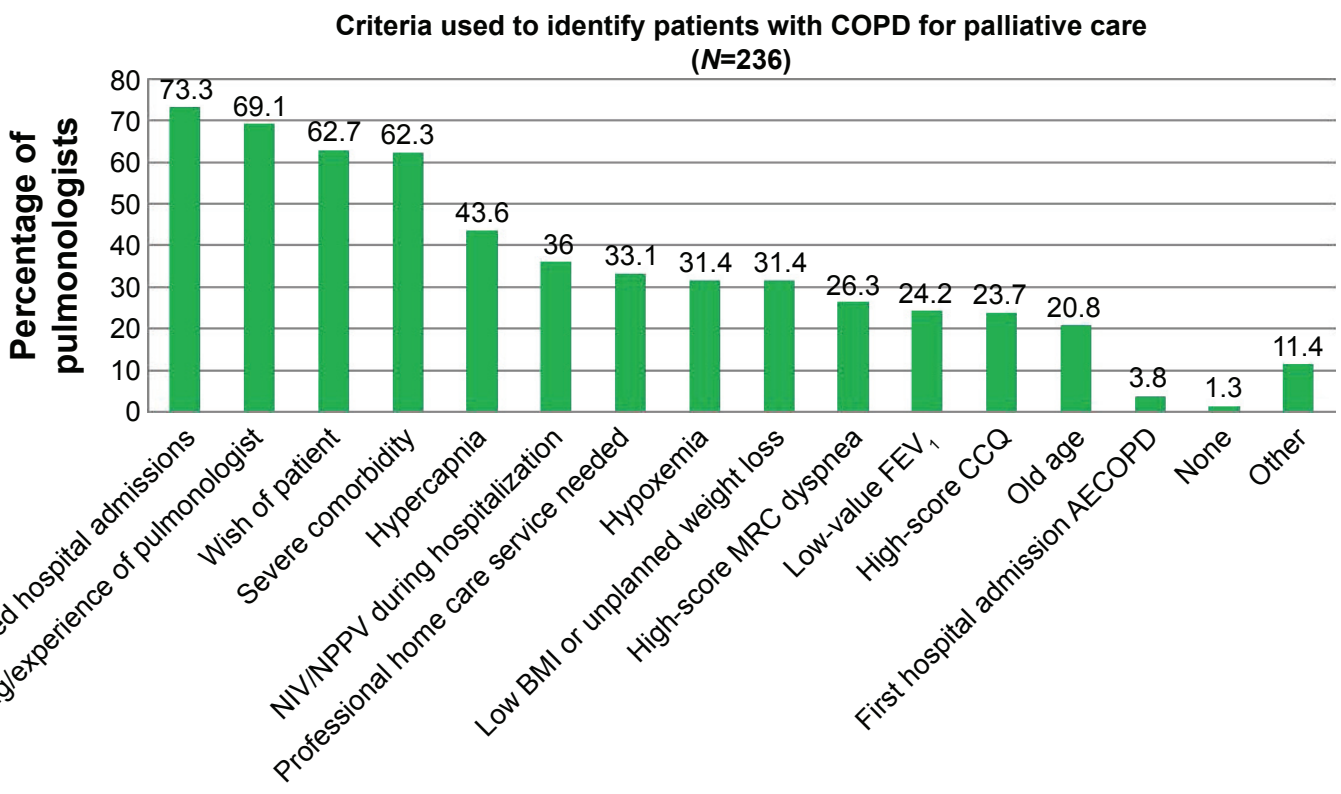

Figure 3 The criteria and the percentage of respondents that mentioned use of each criterion to identify patients with COPD for palliative care. Abbreviations: AECOPD, acute exacerbation COPD; BMI, body mass index; CCQ, clinical COPD questionnaire; FEV , forced expiratory volume in I second; MRC dyspnea, Medical Research Council dyspnea questionnaire; NIV, non invasive ventilation; NPPV, non invasive possitive pressure ventilation.

\section{During hospitalization}

The opinion of respondents about who should organize palliative care for patients with COPD during hospitalization is presented in Figure 6. Most respondents (55.5\%) considered the pulmonologist to perform this task.

\section{In the ambulatory setting}

The opinion of respondents about who should organize palliative care for patients with COPD in the ambulatory setting is presented in Figure 6. Most respondents (71.1\%) considered a multidisciplinary cooperation between pulmonologist, GP, and respiratory nurse specialist to perform this task.

\section{Discussion}

Palliative care for patients with COPD is not yet a common practice. ${ }^{3}$ Since pulmonologists have a central role in providing good quality palliative care for patients with COPD, their view on this subject is important. ${ }^{17}$ There are already survey studies that explore their current working situation regarding palliative care for patients with COPD. ${ }^{18,19}$ This survey study, however, is the first to take the view and wishes of pulmonologists into account in order to guide future research and service development.

Almost all pulmonologists indicated that palliative care for patients with COPD is desirable. To ensure that the best available evidence is translated into everyday clinical practice a Dutch clinical guideline palliative care for patients with COPD has been developed in 2010. ${ }^{16}$ However, about half of the pulmonologists indicated not using this clinical guideline, most often because they were not aware of its existence. This is a cause for concern since low awareness of clinical guidelines may subsequently result in low adherence to guideline recommendations and potentially suboptimal healthcare. ${ }^{20}$ In general, adherence to COPD guidelines is suboptimal and as a consequence barriers to guideline adherence in COPD have been identified. ${ }^{20}$ We recommend taking such barriers into account in order to optimize strategies to ensure effective implementation and better use of clinical guidelines in COPD.

To facilitate timely identification of palliative care in COPD, prognostic models to estimate survival have been developed..$^{21}$ Unfortunately, these population models are of little value to predict survival for individual patients. As such, validated evidence-based criteria to determine the prognosis in advanced COPD are not yet available. ${ }^{9,21}$ A discussion has started among clinicians whether a transition point for the initiation of palliative care in the COPD trajectory exists. ${ }^{22-25}$ Some clinicians argue that in response to the prognostic difficulty, more specific criteria of end-stage COPD need to be explored..$^{23}$ Other clinicians argue that searching further for prognostic criteria that may not exist, will lead to prognostic paralysis. ${ }^{24,25}$ Instead, they promote an integrated early palliative care approach according to needs alongside diseaseoriented care. ${ }^{25}$ Nevertheless, the majority of pulmonologists in our study indicated that they do distinguish a palliative phase in the COPD trajectory (92.2\%).

Several tools have been proposed to identify patients with COPD for palliative care..$^{9,21,26,27}$ The formulated identification 

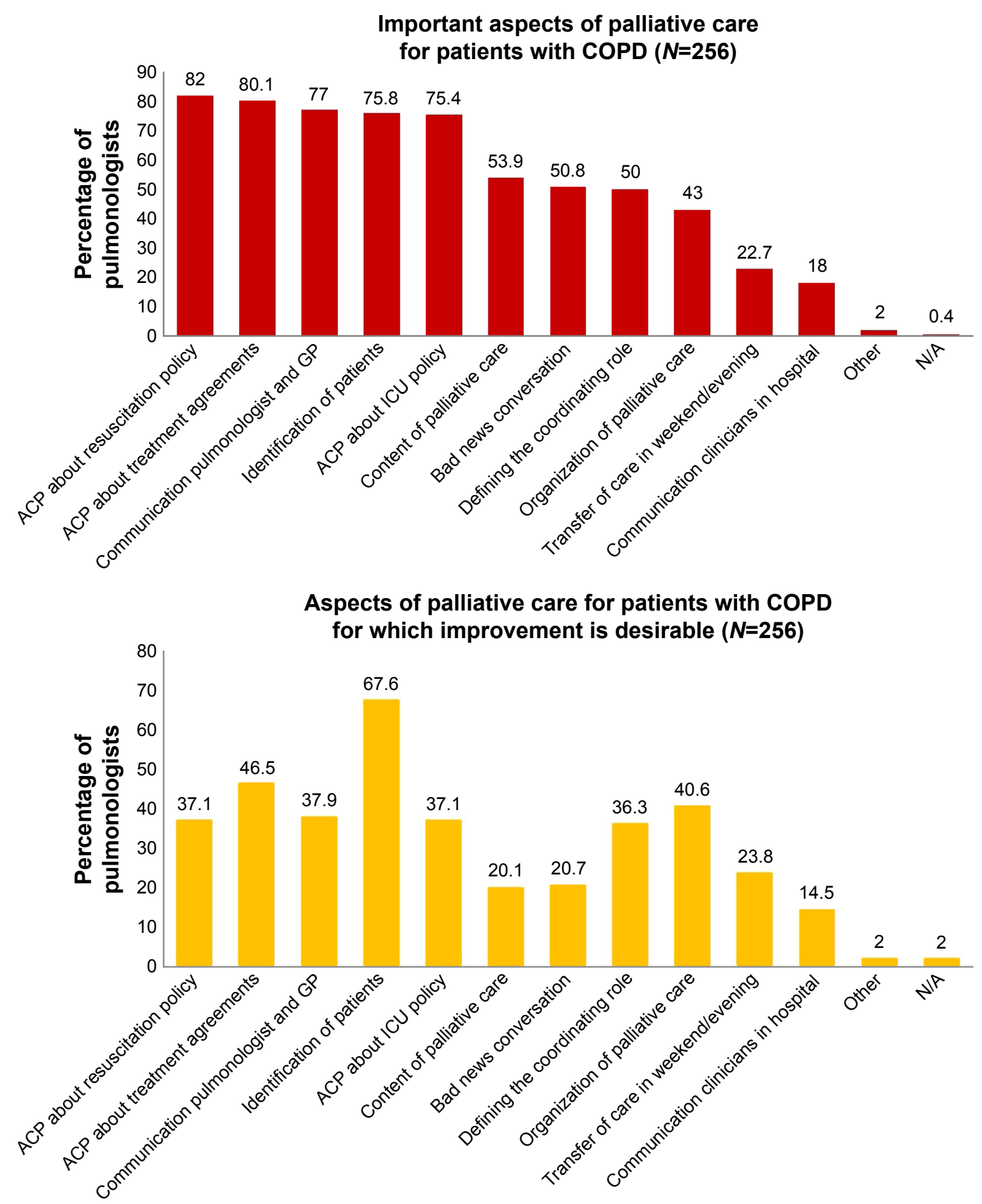

Figure 4 The aspects of palliative care for patients with COPD and the percentage of respondents that mentioned which aspects were important and for which aspects improvement is desirable.

Abbreviations: ACP, advance care planning; GP, general practitioner; ICU, intensive care unit; N/A, not applicable.

criteria in our survey were selected on basis of this literature. All pulmonologists indicated use of several criteria. Four criteria were mentioned by about three-quarters of the pulmonologists, being: repeated hospital admissions for an acute exacerbation of COPD (AECOPD), feeling/experience of the pulmonologist that palliative care is needed, wish of the patient, and severe comorbidity. All other formulated criteria were mentioned by about one-third of the pulmonologists, while some pulmonologists also mentioned as additional aspects, no treatment options left and a negative answer to the surprise question (would I, as pulmonologist, be surprised if my patient would die in the next year?). The fact 
Presence of an SPCT in the hospital and involvement in the care of patients with COPD $(N=256)$

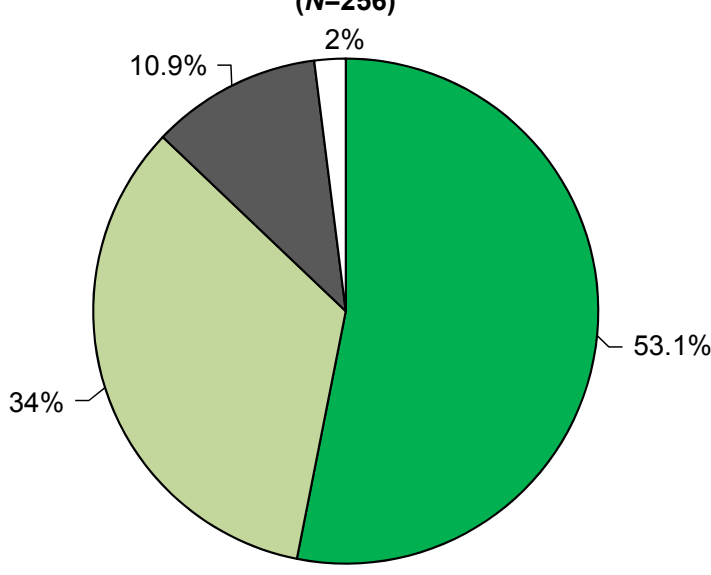

$\square$ Yes, and involved in the care of patients with COPD

$\square$ No

Figure 5 The percentage of respondents that indicated the presence of an SPCT in the hospital and the involvement of the SPCT in the care of patients with COPD. Abbreviation: SPCT, specialized palliative care team.

that criteria of prognosis as well as curability and palliative needs were chosen by the pulmonologists reflects the absence of consensus about the way of identification of patients with COPD for palliative care. ${ }^{11}$

The pulmonologists also indicated which aspects of palliative care for patients with COPD they considered important and for which aspects improvement is desirable. Aspects mentioned to be important by over three-quarters of the pulmonologists were advance care planning (ACP) conversation, communication between pulmonologist and GP, and identification of patients for palliative care. For improvement, only one aspect, identification of patients for palliative care, was mentioned by almost three-quarters of the pulmonologists. The aspects thereafter mentioned for improvement by about two-fifths of the pulmonologists were ACP conversation, organization of palliative care, communication between pulmonologist and GP, and defining the coordinating role. It seems that pulmonologists not only consider the identification of patients for palliative care important but also the most important aspect for improvement. Therefore, we suggest conducting further research into more specific criteria to timely initiate the palliative trajectory. Having such criteria might encourage pulmonologists less familiar with palliative care in COPD to get started. Recently, variables have been identified that could be indicative of poor prognosis for patients hospitalized for an AECOPD and possibly be useful to identify patients for palliative care. ${ }^{28}$ However, the problem of identification of patients with COPD for palliative care is not to predict individual prognosis but to timely start palliative care. Future prospective studies that incorporate these potentially relevant variables should, therefore, focus on identifying criteria for a timely start of palliative care in order to assure that patients with

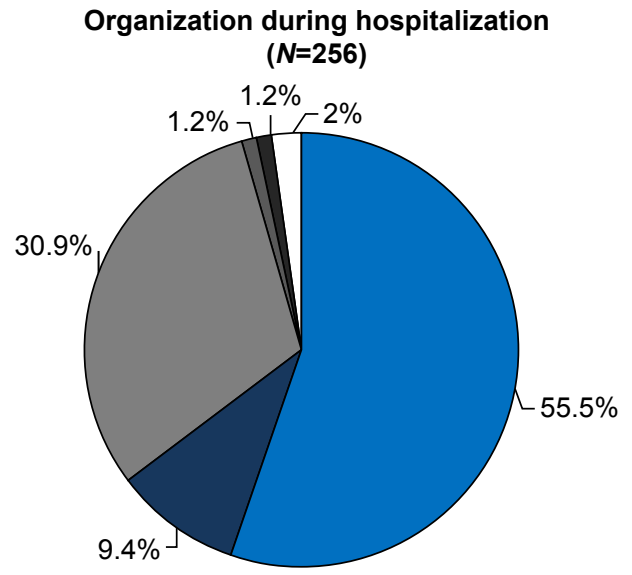

\begin{tabular}{|c|c|}
\hline $\begin{array}{l}\square \text { The personal } \\
\text { pulmonologist } \\
\text { An SPCT in cooperation } \\
\text { with pulmonologists } \\
\text { N/A }\end{array}$ & $\begin{array}{l}\square \text { Specialized } \\
\text { pulmonologists who take } \\
\text { part in an SPCT } \\
\square \text { An SPCT } \\
\square \text { Missing }\end{array}$ \\
\hline
\end{tabular}

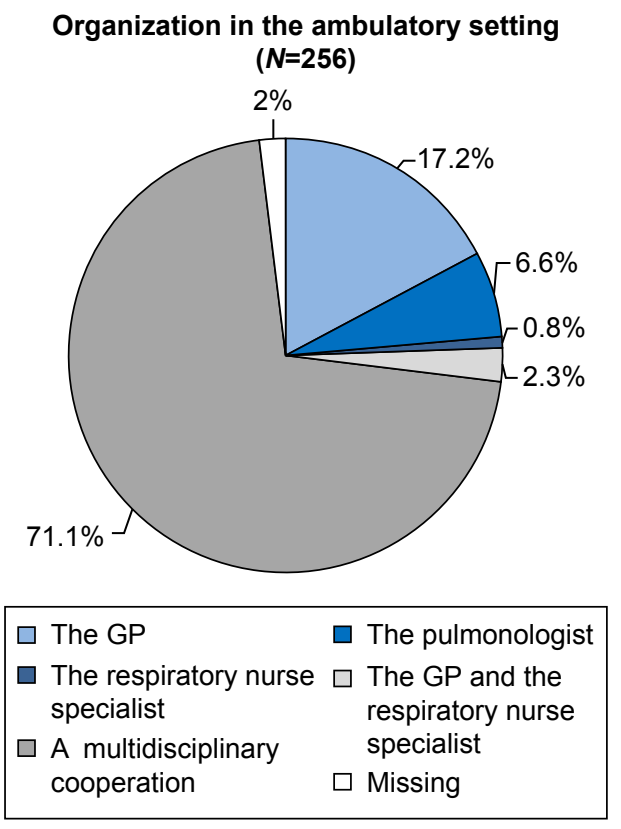

Figure 6 The opinion of respondents about who should organize palliative care for patients with COPD during hospitalization and in the ambulatory setting. Abbreviations: GP, general practitioner; N/A, not applicable; SPCT, specialized palliative care team. 
COPD in need of a palliative approach are not missed out. We think that this way an integrated early use of palliative care alongside disease-oriented care can be accomplished. Beside identification of patients for palliative care, other areas of concern for improvement should preferentially be ACP conversations, communication between pulmonologist and GP, defining the coordinating role and the organization of palliative care.

In order to be able to answer the question, how to organize palliative care in COPD, it is necessary to know the facilities available in the Netherlands. The percentage of hospitals with an SPCT at their disposal, for instance, has increased from $39 \%$ in 2013 to $77 \%$ in $2015 .{ }^{29}$ This growth will probably continue since it is the standard of a foundation emphasizing collaboration in oncology (Stichting Oncologische Samenwerking), that every hospital should have an SPCT by January $2017 .{ }^{30}$ According to this standard, an SPCT should at least consist of two medical specialists and one nurse specialist in palliative care. In our survey, $87.1 \%$ of the pulmonologists, representing 70 of the 73 participating hospital organizations $(95.9 \%)$, indicated the presence of an SPCT in their hospital. However, pulmonologists within 11 hospital organizations $(15.7 \%)$ were not unanimous. The fast increase of hospitals with an SPCT and the fact that we did not define the composition of an SPCT may be the reason for this inconsistency. In the hospital organizations with an SPCT $61 \%$ of the pulmonologists, representing 53 of the 70 hospital organizations, indicated the involvement of the SPCT in the care of patients with COPD. This percentage should, however, be considered with caution since the pulmonologists within 32 hospital organizations (45.7\%) were not unanimous. Some pulmonologists even indicated that theoretically consultation is possible but in practice it is less common. So, although palliative care by an SPCT in hospitals is in development, it seems that the involvement in care of patients with COPD is not yet a common practice.

When asked who should organize palliative care for patients with COPD during hospitalization, more than half of the pulmonologists mentioned the pulmonologist. About three-tenths of the pulmonologists preferred to organize this in cooperation with an SPCT, while about one-tenth preferred specialized pulmonologists who take part in an SPCT. An SPCT, as primarily responsible entity, was hardly mentioned. It shows that during hospitalization, pulmonologists want to be involved in the organization of palliative care for patients with COPD, while there is also room for the involvement of an SPCT. In practice, the input of an SPCT is often demanded in more complex disease trajectories. ${ }^{31}$
Since palliative care in COPD is not a common practice, this implies that pulmonologists should improve their skills of palliative care and the members of the SPCT should be better informed about the management of COPD. ${ }^{11}$

To ensure continuity of palliative care for patients with COPD in the ambulatory setting a coordinated multidisciplinary care approach has been recommended. ${ }^{14}$ Almost three-quarters of the pulmonologists in our study recognized this since they preferred a multidisciplinary cooperation between pulmonologist, GP, and respiratory nurse specialist in the ambulatory setting. To accomplish successful cooperation, we recommend emphasizing the aspects of communication between pulmonologist and GP and defining the coordinating role in training.

Finally, as palliative care is multidisciplinary care, we also recommend exploring the view of other healthcare professionals involved in palliative care for patients with COPD, as well as their incentives and barriers regarding the provision of early palliative care.

Several strengths and limitations should be considered to be able to interpret the findings. This is the first survey study to explore the views and wishes of pulmonologists regarding palliative care for patients with COPD. Furthermore, 85.9\% of hospital organizations were represented by the responding pulmonologists. Like in most surveys, we did not use a validated questionnaire. It is possible that certain questions were not totally unambiguous, and therefore not always interpreted in the same way. Although comparable with other survey studies, ${ }^{32,33}$ the overall response rate of $31.8 \%$ is low and raises concerns whether the results can be generalized to the Dutch population of pulmonologists. Those pulmonologists who participated were probably more interested in palliative care in COPD than nonresponders and will have provided a more favorable view. For this reason, the low response rate will not have influenced our findings that the identification of patients with COPD for palliative care and the organization of such care need improvement.

\section{Conclusion}

Pulmonologists considered palliative care for patients with COPD is desirable. Still many of them did not know about the existence of the palliative care guideline care for people with COPD. We, therefore, recommend that more attention should be paid to the implementation of such guidelines. Most of the pulmonologists distinguished a palliative phase in the COPD trajectory. Many different criteria were used, and there was no consensus whether prognosis, curability, and/or palliative needs should mark the start of palliative care in COPD. The identification of patients with COPD for 
palliative care was not only seen as important but also seen as the most important aspect for improvement. We, therefore, recommend conducting further research into more specific criteria to initiate a timely palliative trajectory.

The organization of palliative care was also mentioned as an aspect for improvement. During hospitalization, pulmonologists indicated that they wanted to be involved in the organization of palliative care for patients with COPD while there was also room for input of an SPCT. Since palliative care in COPD is not a common practice, we recommend that pulmonologists improve their skills of palliative care and the members of the SPCT be better informed about the management of COPD. In the ambulatory setting, most pulmonologists preferred a multidisciplinary cooperation between pulmonologist, GP, and respiratory nurse specialist. Since pulmonologists indicated ACP conversations, communication between pulmonologist and GP, and defining the coordinating role as improvement aspects, we recommend emphasizing these aspects in training.

\section{Acknowledgments}

We would like to thank the members and the administration of the Netherlands Association of Physicians for Lung Diseases and Tuberculosis (NVALT) for their cooperation. This paper was financially supported by a grant of the Netherlands Organization for Health Research and DevelopmentZonMw, The Hague. Project number: 80-82100-98-080. The abstract of this paper was presented at the European Association for Palliative Care (EAPC) 9th World Research Congress, 9-11 June 2016 in Dublin, Ireland as print only abstract and published online in a special edition of Palliative Medicine: http://pmj.sagepub.com/content/30/6/NP1.full. pdfthtml.

\section{Authors' contributions}

All authors contributed toward data analysis, drafting and revising the paper and agree to be accountable for all aspects of the work.

\section{Disclosure}

The authors report no conflicts of interest in this work.

\section{References}

1. Lozano R, Naghavi M, Foreman K, et al. Global and regional mortality from 235 causes of death for 20 age groups in 1990 and 2010: a systematic analysis for the Global Burden of Disease Study 2010. Lancet. 2012;380(9859):2095-2128.

2. Solano JP, Gomes B, Higginson IJ. A comparison of symptom prevalence in far advanced cancer, AIDS, heart disease, chronic obstructive pulmonary disease and renal disease. J Pain Symptom Manage. 2006; 31(1):58-69.
3. Gore JM, Brophy CJ, Greenstone MA. How well do we care for patients with end stage chronic obstructive pulmonary disease (COPD)? A comparison of palliative care and quality of life in COPD and lung cancer. Thorax. 2000;55(12):1000-1006.

4. Addington-Hall JHK. Non-cancer patients as an underserved group. In: Cohen JDL, editor. A Public Health Perspective on End of Life Care. Oxford, UK: Oxford University Press; 2012:151-159.

5. World Health Organization (WHO). WHO Definition of Palliative Care; 2002. Available from: http://www.who.int/cancer/palliative/ definition/en/. Accessed December 15, 2015.

6. Yohannes AM. Palliative care provision for patients with chronic obstructive pulmonary disease. Health Qual Life Outcomes. 2007;5:17.

7. Murray SA, Pinnock H, Sheikh A. Palliative care for people with COPD: we need to meet the challenge. Prim Care Respir J. 2006;15(6): 362-364.

8. Lunney JR, Lynn J, Foley DJ, Lipson S, Guralnik JM. Patterns of functional decline at the end of life. JAMA. 2003;289(18):2387-2392.

9. Curtis JR. Palliative and end-of-life care for patients with severe COPD. Eur Respir J. 2008;32(3):796-803.

10. Patel K, Janssen DJ, Curtis JR. Advance care planning in COPD. Respirology. 2012;17(1):72-78.

11. Dalgaard KM, Bergenholtz H, Nielsen ME, Timm H. Early integration of palliative care in hospitals: a systematic review on methods, barriers, and outcome. Palliat Support Care. 2014;12(6):495-513.

12. Elkington H, White P, Addington-Hall J, Higgs R, Edmonds P. The healthcare needs of chronic obstructive pulmonary disease patients in the last year of life. Palliat Med. 2005;19(6):485-491.

13. Brumley RD. Future of end-of-life care: the managed care organization perspective. J Palliat Med. 2002;5(2):263-270.

14. Spathis A, Booth S. End of life care in chronic obstructive pulmonary disease: in search of a good death. Int J Chron Obstruct Pulmon Dis. 2008; 3(1):11-29.

15. Rocker GM, Simpson AC, Horton R. Palliative care in advanced lung disease: the challenge of integrating palliation into everyday care. Chest. 2015;148(3):801-809.

16. Lung Alliance Netherlands (LAN). [Guideline palliative care for people with COPD]. Richtlijn Palliatieve Zorg voor mensen met COPD. Amersfoort, the Netherlands; 2011. Available from: http://www.oncoline.nl/uploaded/docs/COPD/LAN\%20Richtlijn\%20Palliatieve\%20 Zorg\%20COPD\%20(Pallialine).pdf. Accessed December 15, 2015.

17. Selecky PA, Eliasson CA, Hall RI, Schneider RF, Varkey B, McCaffree DR; American College of Chest Physicians. Palliative and end-of-life care for patients with cardiopulmonary diseases: American College of Chest Physicians position statement. Chest. 2005;128(5): 3599-3610.

18. Strang S, Ekberg-Jansson A, Strang P, Larsson LO. Palliative care in COPD - web survey in Sweden highlights the current situation for a vulnerable group of patients. Ups J Med Sci. 2013;118(3):181-186.

19. Gaspar C, Alfarroba S, Telo L, Gomes C, Barbara C. End-of-life care in COPD: a survey carried out with Portuguese pulmonologists. Rev Port Pneumol. 2014;20(3):123-130.

20. Overington JD, Huang YC, Abramson MJ, et al. Implementing clinical guidelines for chronic obstructive pulmonary disease: barriers and solutions. J Thorac Dis. 2014;6(11):1586-1596.

21. Coventry PA, Grande GE, Richards DA, Todd CJ. Prediction of appropriate timing of palliative care for older adults with non-malignant life-threatening disease: a systematic review. Age Ageing. 2005;34(3): 218-227.

22. Epiphaniou E, Shipman C, Harding R, et al. Coordination of end-of-life care for patients with lung cancer and those with advanced COPD: are there transferable lessons? A longitudinal qualitative study. Prim Care Respir J. 2014;23(1):46-51.

23. Crawford EJ, Moudgil H, Srinivasan K, Naicker T, Ahmad N. Coordination of end-of-life care for patients with lung cancer and those with advanced COPD: a letter of response. NPJ Prim Care Respir Med. 2014; 24:14030. 
24. Kendall M, Buckingham S, Ferguson S, Hewitt N, Pinnock H. We need to stop looking for something that is not there. NPJ Prim Care Respir Med. 2014;24:14031.

25. Epiphaniou E, Shipman C, Harding R, et al. Avoid prognostic paralysis just get ahead and plan and co-ordinate care. NPJ Prim Care Respir Med. 2014;24:14085.

26. Singanayagam A, Schembri S, Chalmers JD. Predictors of mortality in hospitalized adults with acute exacerbation of chronic obstructive pulmonary disease. Ann Am Thorac Soc. 2013;10(2):81-89.

27. Highet G, Crawford D, Murray SA, Boyd K. Development and evaluation of the Supportive and Palliative Care Indicators Tool (SPICT): a mixedmethods study. BMJ Support Palliat Care. 2014;4(3):285-290.

28. Steer J, Gibson GJ, Bourke SC. Predicting outcomes following hospitalization for acute exacerbations of COPD. QJM. 2010;103(11): 817-829.

29. Boddaert M, Douma J, van Aalst B, et al. Palliatieve zorg in Nederlandse ziekenhuizen - Resultaten 2015. [Palliative care in Dutch hospitals - Results 2015]. The Netherlands comprehensive cancer organization, Utrecht: IKNL; 2015. Available from: https:/www.iknl. $\mathrm{nl} /$ docs/default-source/default-document-library/palliatieve-zorg-innederlandse-ziekenhuizen-(2015).pdf?sfvrsn=2. Accessed October 16, 2016. Dutch.
30. Samenwerking SSO. [Cooperation SSO]. Multidisciplinaire Normering Oncologische Zorg in Nederland-SONCOSnormeringsrapport 3. [Multidisciplinary Standardizating of Oncological Care in the Netherlands SONCOS report of standardization 3]. Utrecht: Foundation oncological cooperation (SONCOS); 2015. Available from: http://www.nvmo.org/ files/SONCOS/SONCOS-normeringsrapport_feb_2015.pdf. Accessed October 16, 2016. Dutch.

31. Johnson M, Fallon M. Just good care? The palliative care of those with non-malignant disease. Palliat Med. 2013;27(9):803-804.

32. Fenstad ER, Shanafelt TD, Sloan JA, et al. Physician attitudes toward palliative care for patients with pulmonary arterial hypertension: results of a cross-sectional survey. Pulm Circ. 2014;4(3):504-510.

33. Charalambous H, Pallis A, Hasan B, O’Brien M. Attitudes and referral patterns of lung cancer specialists in Europe to Specialized Palliative Care (SPC) and the practice of early palliative care (EPC). BMC Palliat Care. 2014;13(1):59. 


\section{Supplementary material}

\section{Survey for pulmonologists}

\section{Demographic situation:}

1. What is your position?

Pulmonologist

Pulmonologist in training

2. Are you clinically active?

$\square$ Yes

$\square$ No

3. Name hospital

4. Location (if applicable)

5. Place of residence hospital

6. Gender

Male

Female

7. a. How many pulmonologists work in your association of pulmonologists (or hospital)?

b. Number of males/females?

........ Males

Females

\section{Questions palliative care for patients with COPD}

1. Is in your opinion palliative care for patients with COPD desirable?

Yes

$\square$ No

2. Do you distinguish a palliative phase in the COPD disease trajectory?

$\begin{array}{ll}\square \text { Yes } & \text { (go to question 4) } \\ \square \text { Sometimes } & \text { (go to question 4) } \\ \square \text { No } & \text { (go to question 3) }\end{array}$

3. If not, what is the reason of this? (more than one answer possible) (go to question 7)

$\square$ In my opinion, there is no distinction between curative and palliative care in COPD

I don't have time for it

I find the criteria for the start of palliative care in COPD difficult
A Specialized Palliative Care Team (SPCT) is not available for patients with COPD

Other, namely

4. Do you use the guideline palliative care for people with COPD (2011)?

$\begin{array}{ll}\square \text { Yes } & \text { (go to question 6) } \\ \square \text { No } & \text { (go to question 5) }\end{array}$

5. If not, what is the reason for this? (more than one question possible)

I was not aware of the existence of this guideline

I find this guideline unclear

Applying the guideline takes too much time

The scientific basis of the guideline is to my opinion questionable

The criteria for the start of palliative care in COPD are unclear

Other, namely

6. What criterion/criteria do you use for the start of palliative care in patients with COPD? (more than one answer possible)

First hospital admission for an acute exacerbation COPD (AECOPD)

Repeated hospital admissions for an AECOPD

Hypoxemia (stable and/or at discharge)

Hypercapnia (stable and/or at discharge)

NIV/NPPV necessary during hospitalization

Professional home care service needed for personal care

Severe comorbidity

Low value FEV,

Low BMI or unplanned weight loss

Old age

High score CCQ (=Clinical COPD Questionnaire)

High score MRC dyspnea questionnaire

Feeling/experience of pulmonologist

Wish of patient

Other, namely

None

7. In your opinion, what are important aspects of palliative care for patients with COPD? (more than one answer possible)

Identification of patients for palliative care

Bad news conversation

Advance Care Planning (ACP) conversation about resuscitation policy

ACP conversation about treatment agreements 
(eg, enteral tube feeding, antibiotics, hospitalization, palliative sedation, mechanical ventilation)

ACP conversation about ICU policy

Content of palliative care

Organization of palliative care

Defining the coordinating role

(eg, pulmonologist/respiratory nurse specialist/ specialized palliative care team/GP)

Communication with other professionals within the hospital

Communication between pulmonologist and GP

Transfer of care in the weekend/evening

Other, namely

N/A

8. In your opinion, for which aspects of palliative care for patients with COPD is improvement desirable? (more than one answer possible)

Identification of patients for palliative care

Bad news conversation

Advance Care Planning (ACP) conversation about resuscitation policy

ACP conversation about treatment agreements (e.g. enteral tube feeding, antibiotics, hospitalization, palliative sedation, mechanical ventilation)

ACP conversation about ICU policy

Content of palliative care

Organization of palliative care

Defining the coordinating role

(eg, pulmonologist/respiratory nurse specialist/ specialized palliative care team/GP)

Communication with other professionals within the hospital

Communication between pulmonologist and GP

Transfer of care in the weekend/evening

Other, namely

N/A

9. Does the hospital have a Specialized Palliative Care Team (SPCT) at their disposal?

$\square$ Yes

If yes, are they also involved in the care of patients with COPD?

\section{Yes}

$\square$ No

$\mathrm{No}$
10. Who should in your opinion organize the delivery of (proactive) palliative care for patients with COPD during hospitalization? (only one answer possible)

The personal pulmonologist. Every pulmonologist provides (proactive) palliative care to their own patients with COPD

A specialized pulmonologist who take part of a SPCT

A SPCT in close cooperation with pulmonologists $\mathrm{N} / \mathrm{A}$

11. Who should in your opinion organize the delivery of (proactive) palliative care for patients with COPD in the ambulatory setting? (only one answer possible)

The GP

The pulmonologist

$\square$ The respiratory nurse specialist

The GP and the respiratory nurse specialist

A multidisciplinary cooperation (GP/pulmonologist/ respiratory nurse specialist)

$\mathrm{N} / \mathrm{A}$

12. What aspects of palliative care in COPD did you miss or do you think should be developed in the near future? 
International Journal of COPD

\section{Publish your work in this journal}

The International Journal of COPD is an international, peer-reviewed journal of therapeutics and pharmacology focusing on concise rapid reporting of clinical studies and reviews in COPD. Special focus is given to the pathophysiological processes underlying the disease, intervention programs, patient focused education, and self management protocols.

This journal is indexed on PubMed Central, MedLine and CAS. The manuscript management system is completely online and includes a very quick and fair peer-review system, which is all easy to use. Visit http://www.dovepress.com/testimonials.php to read real quotes from published authors 